\title{
Energizadas pelo movimento de mulheres \#NiUnaMenos, as equipes de futebol feminino desafiam os patriarcas do esporte-rei da América Latina
}

\author{
Energized by the \#NiUnaMenos Movement, Women's Football Teams \\ Take on the Patriarchs of the Beautiful Game in Latin America.
}

\author{
Brenda Elsey \\ Hofstra University, Nova York/EUA \\ Doutora em História, Universidade do Estado de Nova York \\ brenda.elsey@hofstra.edu \\ Larissa Brainer (tradução) \\ Jornalista e Diretora de Comunicação Social \\ da Organização love.fútbol
}

\begin{abstract}
RESUMO: Este ensaio aborda algumas questões emergentes que gravitam em torno do futebol feminino na América Latina, como a falta de reconhecimento das próprias instituições que dirigem o futebol. Em 2108, algumas seleções - portoriquenha, jamaicana e argentina - promoveram protestos em campo já que as federações de futebol vez ou outra ignoram as solicitações das jogadoras. Levar o descontentamento ao gramado tem ajudado essas mulheres a chamar a atenção para a sua causa.
\end{abstract}

PalaVRas-Chave: Futebol Feminino; Futebol e política; Futebol na América Latina.

ABSTRACT: This essay addresses some emerging issues that have a bearing on women's football in Latin America, such as the lack of recognition of the very institutions that run football. In 2108, some selections - Puerto Rican, Jamaican and Argentine - promoted protests in the field since the football federations occasionally ignore the requests of the players. Bringing dissatisfaction to the lawn has helped these women to draw attention to their cause.

KEYWORDS: Women's Football; Football and Politics; Football in Latin America. 
Em agosto de 2018, ${ }^{1}$ as seleções femininas de futebol da Argentina e de Porto Rico se enfrentaram pela primeira vez na história. A partida foi também o primeiro amistoso internacional jogado por Porto Rico. No início do confronto, as jogadoras porto-riquenhas reuniram-se no centro do campo e apontaram para os ouvidos. Guardando respeito, as argentinas chutaram a bola para fora do campo e esperaram. Cerca de cinco mil espectadores - uma boa quantidade para uma partida de futebol na ilha - as apoiaram. 0 público compreendeu que o gesto significava que as jogadoras estavam pedindo que as escutassem.

Poucos meses antes, suas rivais argentinas instauraram o gesto de levar as mãos às orelhas, tanto nas comemorações dos gols como nas fotos oficiais da Copa América, o torneio feminino mais importante da América do Sul. As jogadoras tomaram para si um gesto consagrado pelo famoso Juan Román Riquelme. Em 2001, o jogador o fez para protestar contra os dirigentes do seu clube, Boca Juniors, então comandado por Mauricio Macri, atual presidente da Argentina.

Pouco depois do protesto porto-riquenho, as jogadoras da seleção de Trinidad e Tobago utilizaram as redes sociais para pedir doações a fim de chegar aos Estados Unidos para competir no campeonato da Confederação de Futebol da América do Norte, Central e Caribe (CONCACAF) em busca da possibilidade de jogar o Mundial Feminino. Duas semanas antes do começo do torneio, as jogadoras não tinham hospedagem confirmada, técnico e nem campo para treinar. Lauren Silver, da seleção jamaicana conhecida como "Reggae Girlz", publicou uma história no Instagram em que ela confirmava que, como as outras seleções do Caribe, faltando duas semanas para a competição, as jogadoras jamaicanas ainda não tinham recebido remuneração, campo para treinar, ou nenhum planejamento para viajar para as eliminatórias da CONCACAF. Para aprofundar a humilhação, ao ser entrevistada em um podcast recente, Silver contou que a federação não havia fornecido as camisetas do time, que teve que usar as da seleção masculina, com a legenda "Reggae Boyz".

\footnotetext{
1 Ensaio publicado, em dezembro de 2018, na Revista Rosa. Disponível em: http://bit.ly/309oJpT.
} 
Os protestos em campo se tornaram um lugar comum já que as federações de futebol vez ou outra ignoram os e-mails, as ligações e as solicitações de reuniões das suas jogadoras. Levar o descontentamento ao gramado tem ajudado essas mulheres a chamar a atenção para a sua causa. A força que essas ações coletivas têm tomado demonstra que elas estão se observando, contatando e apoiando mutuamente. Durante os últimos três anos, tem surgido uma onda de protestos no futebol feminino latino-americano. Começaram no Cone Sul e se estenderam por toda a região. As demandas das jogadoras variam desde o acesso a vestiários até a obtenção de seguros médicos, passando por relatórios claros sobre a forma que as federações gastam os fundos para seu desenvolvimento. Hoje, os patriarcas do esporte-rei se encontram frente a uma série de ações coletivas inspiradas pelo movimento \#NiUnaMenos. Se obtiverem sucesso, as jogadoras poderiam revolucionar o passatempo mais popular na América Latina.

\section{UMA LONGA HISTÓRIA DE OMISSÃO}

O apagamento da longa história do futebol feminino por jornalistas, dirigentes e até acadêmicos tem sido usado para aplacar os protestos de suas jogadoras, e para justificar a negativa de igualdade de recursos. A verdade é que as mulheres começaram a jogar futebol na América Latina no início do século XX. Desde o começo, encararam zombarias, proibições e uma violenta exclusão. Em que pese essa hostilidade, as futebolistas conseguiram uma grande quantidade de notáveis conquistas. Um exemplo é que em 1940 as equipes femininas do Rio de Janeiro haviam criado uma liga vibrante que inclusive viajava por todo o país, chegando até a jogar diante do presidente Getúlio Vargas na inauguração do estádio Pacaembu de São Paulo. No ano seguinte, o governo de Vargas proibiu via decretolei que as mulheres jogassem futebol.

$\mathrm{Na}$ Costa Rica, as mulheres da equipe Deportivo Feminino atuaram como embaixadoras do esporte durante a década de 1950. Viajaram à Colômbia, Curaçao, El Salvador e Honduras, difundindo a paixão pelo futebol feminino. Por sua vez, a liga feminina do México sediou o segundo campeonato mundial de futebol feminino em 1971. A final desse torneio levou cerca de 110.000 espectadores que 
lotaram o Estádio Azteca, de forma completamente independente da Federação Internacional de Futebol (FIFA). Apesar dos esforços para atrair mais seleções além das europeias, a única representante latino-americana foi a seleção argentina. A delegação alviceleste tinha algumas das jogadoras mais velhas, veteranas de seus clubes locais de Buenos Aires e La Plata. Para essas atletas foi tão trabalhoso levantar recursos para viajar às partidas que chegavam em grupos separados para economizar dinheiro com a hospedagem. 0 treinador nunca conseguiu ir para o México, e elas tiveram que conseguir um treinador local para cumprir o regulamento. Conquistas como o torneio de 1971 levaram os clubes, as federações e a FIFA a colocar ainda mais barreiras para as mulheres que queriam jogar futebol, como multas para os clubes que permitissem que equipes femininas treinassem em suas dependências. Quando, por fim, a FIFA decidiu organizar uma versão feminina do Mundial masculino, 20 anos depois, o fez nos seus próprios termos, excluindo por completo as mulheres das posições de liderança.

As instituições futebolísticas não apoiaram o progresso das atletas em nenhum nível de sua organização. Somente depois que a FIFA decidiu que o futebol feminino era um mercado inexplorado, Sepp Battlet - o desacreditado presidente da FIFA - declararia em 2011: “Nós sempre acreditamos que o futuro do futebol é feminino".

No entanto, com o resultado dos combinados latino-americanos que disputaram o Mundial Feminino de 2015, rapidamente as federações voltaram a deixar de lado as suas seleções femininas.

Para 2016, a maioria das seleções femininas da Confederação Sul-Americana de Futebol (CONMEBOL) estava fora dos rankings da FIFA, entre elas Argentina, Bolívia, Chile, Paraguai, Peru e Uruguai. Suas federações não organizaram partidas, nem responderam aos convites, nem convocaram suas seleções por mais de um ano. As jogadoras estavam em um estado de confusão geral.

A situação escandalosa em que se encontrava o futebol feminino levou as jogadoras à ação, de formas distintas, mas conectadas. É necessário compreender suas reações dentro do contexto de movimento global no futebol feminino. Não é coincidência que os movimentos que fizeram mais barulho, os da Argentina, do 
Brasil e do Chile, ocorreram nos países que têm mais disparidade entre suas seleções masculina e feminina, tanto em resultados quanto em recursos.

\section{AS FUTEBOLISTAS SE REBELAM}

O Chile é um desses exemplos. A geração atual de jogadoras chilenas começou em sua adolescência, nas divisões mais baixas da seleção nacional. Entre 2008 e 2014, durante o mandato de um presidente da federação que lhes deu apoio, chegaram a estar em 38으 lugar no ranking da FIFA. No entanto, em 2016, encontravam-se relegadas à categoria de "inativas", na lanterna dessa classificação. As jogadoras reagiram formando a primeira associação nacional da América Latina, a Associação Nacional de Jogadoras de Futebol Feminino (ANJUFF): organização que buscou e acabou conseguindo tornar-se membro do sindicato dos jogadores. A ANJUFF trabalhou em conjunto com a recém-formada Corporação de Fomento ao Futebol Feminino (CONFFUF), um grupo dedicado a apoiar a seleção nacional, e juntos conseguiram convencer a federação chilena de ser anfitriã da Copa América Feminina, um marco que resultou na classificação como seleção para o Mundial Feminino da França 2019, sendo a primeira vez que conseguiram esse resultado na história. Na atualidade, conseguiram galgar até o posto 39ำ do ranking da FIFA e recentemente jogaram as partidas amistosas contra a seleção feminina dos Estados Unidos. A ANJUFF também se encontra em processo de negociar contratos profissionais com os clubes chilenos, cuja liga feminina tem sido, na prática, amadora.

Na vizinha Argentina, as jogadoras se encontravam em situação similar. Não tiveram treinador na temporada 2015-2016 e não jogaram por meses. Além disso, a Associação de Futebol Argentino (AFA) não havia pagado as jogadoras sua remuneração pelos poucos treinos convocados. 0 valor pago por treino é de aproximadamente nove dólares, o que serve apenas para custear o transporte até o centro de treinamento que a AFA mantém em Ezeiza, fora de Buenos Aires. A seleção convocou uma paralisação geral em novembro de 2017. As jogadoras enviaram uma carta coletiva à AFA, a qual explicava que não compareceriam aos treinos nem às partidas até que a federação lhes concedesse um mínimo de recursos, incluindo remunerações, treinador, campos de grama, vestiários e 
horários de viagem que não fossem desumanos. A AFA respondeu contratando novamente o treinador Carlos Borello e pagando as remunerações devidas. Foi esse time - capitaneado por Estefanía Banini - que estava na foto da Copa América fazendo sinal com as mãos para amplificar o alcance de suas orelhas, exigindo que as escutassem.

Apesar das concessões, hoje é impossível que alguma mulher argentina possa viver da prática profissional de futebol, sem importar seu talento. A liga profissional da Argentina tem existido intermitente, a qual tem levado suas melhores jogadoras para buscar oportunidades em ligas recém-criadas, como as da Colômbia, Estados Unidos e China, entre outras. As jogadoras mais bem pagas do clube mais popular, Boca Juniors, recebem cerca de 200 dólares por mês durante a temporada. As jogadoras têm aproveitado as oportunidades que o regulamento da CONMEBOL gerou, já que exige dos clubes que participam da Copa Libertadores, o torneio sul-americano de clubes, também tenham times femininos. No que tange às políticas institucionais, as futebolistas argentinas também têm estabelecido relações com políticos interessados em igualdade de gênero no interior do esporte. Por exemplo, a congressista Mayra Mendoza propôs uma lei que garante as competições femininas de nível nacional sejam transmitidas pela televisão pública. Porém, as mulheres fazem muito com o pouco que lhes dão. Quando a AFA se esqueceu de enviar o troféu da Copa de Prata, as mulheres do clube Estudiantes de La Plata celebraram alegremente em torno de uma jarra de água vazia.

Talvez não exista outro lugar que o futebol feminino provoque ao mesmo tempo tanta hostilidade e tanta paixão como o Brasil. Na esteira da proibição de 40 anos que o futebol feminino sofreu entre 1941 e 1979, quase de imediato as brasileiras tornaram-se uma potência continental. A capacidade de competir contra as melhores equipes do mundo, apesar de contar com uma fração dos recursos, é algo que pode causar espanto. No entanto, também lutam contra outros desafios: sua federação, a Confederação Brasileira de Futebol (CBF) é famosa por corrupção. A CBF tem sido incapaz de manter à tona uma liga doméstica, e as jogadoras jamais contaram com salários estáveis no Brasil. 
Em 2016, depois de anos ignorando os pedidos por mulheres em posições de liderança, a CBF designou Emily Lima como a primeira mulher a treinar a seleção feminina. Apesar de um histórico bem-sucedido, despediram Lima sem qualquer explicação em setembro de 2017, o que levou ao retorno do treinador anterior, Oswaldo Fumeiro Álvarez - mais conhecido como Vadão - recém desligado como técnico da equipe masculina do Guarani. As mulheres denunciaram o fato, e a demissão de Lima se tornou um foco de protestos. Veteranas e jogadoras em atuação escreveram petições e algumas de aposentaram da atividade, incluindo a estrela Cristiane (Rozeira de Souza Silva), que jogou em ligas do Brasil, China, França, Alemanha, Suécia e Estados Unidos.

A pressão levou a federação a formar uma comissão para responder à demissão de Lima, que incluía Silvana Goellner, ativista e professora da Universidade Federal do Rio Grande do Sul. Contudo, quando a comissão apresentou à CBF um plano de ação para a crise, a federação respondeu desmantelando a comissão dois meses depois. Apesar da falta de apoio institucional, Goellner reiterou que a comissão não abandonaria a luta, entendendo que estava ligada a temas mais amplos de justiça social no Brasil. "Quem mobilizou esse protesto são mulheres que talvez não se reconheçam como feministas, no entanto, compreende que as lutas do movimento feminista são necessárias e fundamentais para empoderar a mulher no futebol e para além dele".2

\section{DESAFIANDO O SEXISMO DENTRO E FORA DO CAMPO}

A hostilidade contra as mulheres atletas na América Latina caminha de mãos dadas com a homofobia tanto no interior das instituições estatais e, de modo mais informal, na prática cultural cotidiana. Os programas de Educação Física, desde o começo ao fim do século XIX, ensinavam aos estudantes que as meninas eram biologicamente inferiores, mentalmente instáveis e frágeis. Além disso, os "especialistas" advertiam às alunas que praticar passatempos tradicionalmente masculinos, como o futebol, pervertia o desenvolvimento heterossexual das

\footnotetext{
${ }^{2}$ Em entrevista concedida via WhatsApp para a autora do texto em 2017.
} 
meninas e podia até afetar sua saúde maternal. Ao mesmo tempo, aceitava-se amplamente o futebol como veículo de desenvolvimento da masculinidade correta, dificultava-se a prática para mulheres e meninas. As mulheres que se dedicavam aos esportes de equipe enfrentaram maior escrutínio que aquelas que se dedicavam aos esportes individuais como o tênis. Em parte, a associação do tênis, uma tradição branca e britânica, ajudou a facilitar sua aceitação.

Não obstante, existia algo de perigoso nos esportes coletivos, em que as mulheres se tocavam, viajavam juntas e se apoiavam mutuamente. Ao longo da história, as futebolistas - tanto aquelas que se identificam como LGBTQ+ como aquelas que não - têm sofrido abuso homofóbico de parte das federações, dos professores e até dos vizinhos. Como recorda a ex-capitã brasileira, Sisleide do Amor Lima, a "Sissi": "Sofríamos na seleção, havia consequências... Os treinadores nos diziam para não sairmos do armário. Se alguém era gay, podia não ser convidada, não convocada. Iriam excluir".

O desempenho da feminilidade em campo tinha tanta importância para a federação paulista que até a década de 1990 estipulava que nos seus torneios somente podiam jogar mulheres com cabelo comprido o suficiente para fazer um rabo de cavalo.

A ausência de prestação de contas da FIFA, da CONMEBOL e das federações nacionais torna quase impossível saber quanto apoio recebe o futebol feminino diretamente da FIFA. Supostamente, 15\% dos fundos para o desenvolvimento da FIFA é designado para as mulheres. Isso significa que cada federação nacional deveria gastar ao menos 37.500 dólares por ano no futebol para meninas e mulheres. No entanto, não existe um programa de prestação de contas que obrigue uma confederação a mostrar como gasta esse dinheiro, e a CONMEBOL não tem um sistema que garanta que os recursos cheguem às mulheres dentro das federações. A falta de transparência incentiva a corrupção e o desvio de dinheiro para o desenvolvimento das seleções masculinas. Em janeiro de 2018, a FIFA apresentou uma nova estrutura de desenvolvimento, o FIFA Forward, que reunia em um único grande grupo os recursos para o desenvolvimento feminino e juvenil. 
Aparentemente, inclui maiores exigências de auditoria e maiores incentivos para fomentar o futebol feminino. Ainda assim, não está claro quanto será obrigatório que as federações gastem com atletas mulheres.

A energia renovada do futebol feminino na América Latina se constrói sobre uma vida de trabalho de ativistas de base, como Lorena Berdula, uma das primeiras treinadoras com licença AFA. Como professora de Educação Física da Universidade Nacional de La Plata (UNLP), esteve entre as primeiras que trouxeram a ideia de mudar de futebol feminino para futebol feminista. Por quase 20 anos, Berdula e outras ativistas do futebol de mulheres e meninas têm participado de trabalhos e oficinas por todo o país, autoconvocados e democráticos, para "explicar o futebol feminino como uma forma de questionar as estruturas patriarcais em que vivemos, e de acessar o direito de desfrutar de um esporte tão popular como o futebol". Os departamentos de Educação Física que apresentam uma perspectiva sociológica crítica, como o da UNLP, têm preparado uma geração de estudantes para transformar as concepções de esporte e gênero em escolas públicas, equipes universitárias e clubes locais.

Talvez seja paradoxal que ao longo da história, o esporte não tenha ocupado uma parte significativa das agendas feministas, apesar do foco na integridade do corpo feminino. Todavia, numerosos estudos demonstram os profundos benefícios que a prática esportiva oferece a mulheres e meninas. Além disso, no coração da luta por igualdade de gênero nos esportes, se encontram temas como acesso ao espaço público, ao tempo livre, direitos de trabalho e a representação da comunidade. $\mathrm{O}$ futebol não é só um dos espaços mais estritamente segregados na América Latina, mas também é central para as identidades comunais, nacionais e continentais. Talvez as atletas, muitas delas de classe operária, de cor, ou queer, possam, por fim, sentir que o movimento feminista, em particular o \#NiUnaMenos, é interseccional o suficiente para representá-las. A partir do seu incipiente foco no feminicídio na Argentina, \#NiUnaMenos conseguiu expandir as compreensões populares da violência de gênero e abordou direitos reprodutivos, assédio sexual e os preconceitos midiáticos. Em 2016, este coletivo organizou uma paralisação geral de mulheres, bem como manifestações de rua massivas na Argentina, Bolívia, Brasil, Chile, El Salvador, Guatemala, México, Paraguai, Peru, Porto Rico e Uruguai. 
\#NiUnaMenos não só moldou os protestos das jogadoras, mas também às maneiras com que as sócias dos clubes e as torcedoras organizadas participam do futebol. Há muito tempo que os estádios de futebol são lugares perigosos para as mulheres, porém as torcedoras têm começado a responder com mais rapidez e energia aos incidentes de assédio sexual e violação. Em maio de 2018, um grupo de homens com camisetas do Universidad de Chile violaram uma mulher que passava próximo ao Estádio Nacional. 0 incidente levou as torcedoras do time a unir forças com suas colegas das equipes rivais, Colo-Colo e Universidade Católica, para discutir como prevenir a violência de gênero nos jogos de futebol.

Existem ainda novas organizações de torcedoras feministas que estão criando comissões de gênero e que estão reescrevendo estatutos antiquados, que estão questionando o sexismo, a homofobia e o racismo nas letras dos cânticos populares. Estão também começando a criar espaços para proteger as mulheres e a quem se identifica como LGBTQ+. Durante a última marcha de 25 de julho pela legalização do aborto no Chile, as torcedoras de futebol marcharam juntas pela primeira vez. Enquanto isso, na Argentina, a comissão de gênero de Ferrocarril Oeste, da segunda divisão, escreveu uma carta aberta pedindo aos diretores do clube bonaerense para se expressarem publicamente a favor da descriminalização do aborto.

É fundamental notar a interseção entre o feminismo e os esforços contra a privatização que ocorre dentro dos clubes esportivos. No século XX, os clubes de futebol da América Latina, à diferença dos europeus, se estabeleceram como organizações sem fins lucrativos. Essa modalidade de propriedade compartilhada significou que os sócios arquitetaram clubes com uma estrutura democrática, que se tornaram focos de participação comunitária. No entanto, durante as décadas de 1980 e 1990, os clubes se endividaram gravemente como resultado de altos custos operacionais, de pouco público nos estádios, da corrupção e da exportação de seus melhores talentos à Europa. Por toda a região, os clubes se viram diante de pressões para serem privatizados, em diferentes formatos. Por exemplo, com uma suspeita quebra em 2002, uma sociedade anônima (Blanco y Negro) tomou conta da administração e dos ativos do Colo-Colo do Chile por 30 anos, em troca do pagamento da dívida do clube. 0 clube social e esportivo Colo-Colo viu como foram despojados de seus benefícios, reduzindo a entidade (CSD) a dirigir "atividades 
sociais" e a uma representação minoritária na direção da Sociedade Anônima. 0 fato de que o presidente do Chile, Sebastián Piñera, era um importante investidor de Blanco y Negro politizou o tema ainda mais. Em sua luta contra a guinada empresarial para apoderar-se do Colo-Colo, o CSD encontrou apoio nas suas sócias, que acabaram formando uma comissão de gênero.

Para muitas colocolinas, a privatização do clube se opõe completamente ao entendimento da prática feminista e da crítica ao capitalismo como a raiz da desigualdade, especificamente a de gênero. Daniela Molinet, sócia membra da comissão, explica: “Ao longo do processo de luta contra a turva sociedade anônima houve um aumento constante na participação feminina no interior da organização". Os defensores do clube social se deram conta que incluir atores sociais que antes tinham sido excluídos, além de ajudar a causa, é a atitude correta na luta por uma organização mais democrática e por mais integração social. Como disse Molinet: "A comissão se declara feminista. Isto não é casualidade, é uma resposta à vontade de integrar as mulheres à reconstrução do tecido social do Clube".

A intensa atividade em torno do futebol feminino culminou em uma reunião histórica no dia 24 de agosto de 2018, na sede das Nações Unidas em Santiago do Chile. O fórum reuniu jogadoras da Argentina, Brasil, Chile, Colômbia, Uruguai e Venezuela. Representantes do sindicato internacional de futebolistas, FIFPro, deram conta das formas com que as jogadoras têm se organizado ao redor do mundo para conseguir melhores condições de trabalhos. 0 fórum foi possível graças ao apoio dos aliados de FIFPro, junto à rede FARE (Futebol Contra o Racismo na Europa).

“Decidimos criar um movimento nesta região do mundo para levantar nossa voz e desenvolver construtivamente o futebol feminino na América Latina", explica Camila García, uma das primeiras mulheres a fazer parte do comitê executivo da FIFPro e cofundadora da ANJUFF. "A ideia é permitir que as jogadoras desenvolvam uma carreira sustentável e alcancemos o potencial de imenso talento que temos", acrescenta.

Por restrições de orçamento e agenda, nem todas as federações puderam participar, porém a organização espera criar um evento anual e uma associação internacional. Durante a reunião, era possível sentir a sensação de urgência e 
preocupação. A jogadora uruguaia Valeria Colma enfatizou a importância de aproveitar este momento de atividade enérgica, assim como o movimento transnacional pelos direitos das mulheres. Muitas das jogadoras perguntaram a suas colegas colombianas como vai a liga, recém-formada. Catalina Usme suspirava e olhava para baixo, dizendo que as jogadoras estavam dando tudo de si para que seja um sucesso. Sua companheira de equipe, Orianica Velásquez, disse que queria voltar da Colômbia com a seguinte mensagem para suas companheiras: "tem gente que se importa conosco, gente que quer nos ajudar". Velásquez refletiu: "Aprendemos que hoje muitas de nós podemos viver do futebol, podemos representar os nossos países e famílias, graças às mulheres do século XX que disseram não ao machismo. Talvez em mais cem anos, a história possa dizer que eu formei parte de um grupo de mulheres que impulsionou umas às outras e transformou a mentalidade das pessoas".

Recebido para publicação em: 10 maio 2019. Aprovado em: 23 maio 2019. 